\title{
A SIMPLE INEXPENSIVE METHOD FOR ESTIMATING UNDERWATER WEIGHT
}

\author{
T. R. THOMAS, Ph.D.* and P. L. COOK, M.S.t \\ *Director Exercise Physiology Lab., Robinson Gymnasium, University of Kansas, \\ Lawrence, Kansas 66045 \\ tInstructor of Physical Education, Department of Physical Education, Earlham College, \\ Richmond, Indiana 47374
}

\begin{abstract}
A description is given of a simple, inexpensive and versatile method for estimating underwater weight. The use of a portable stock tank allows the determination of \% Fat by underwater weighing without requiring a swimming pool, built-in tank, or special facility. Twenty-eight college students were weighed on two separate testing sessions 24-48 hours apart. Ten trials were performed at each session. The mean of the last five trials was used in determining underwater weight. The test-retest reliability coefficient was high, $r=0.98$, and most of the successive trial correlations were above 0.99. The mean \% Fat for the women $(N=9)$ was $22.2 \pm 5.9$ and for the men $(N=19)$ was $13.7 \pm 5.1$.
\end{abstract}

Key Words: percent body fat, body density, hydrostatic weighing.

\section{INTRODUCTION}

The determination of the percentage of body fat $(\%$ Fat) has gained increasing emphasis as a factor in physical fitness. Obesity and overweight have been associated with the susceptibility to cardiovascular disease, and the use of \% Fat determinations may be useful in estimating more optimal weights for most individuals. Coaches and athletes are more frequently using \% Fat measures as a means of evaluating training programmes and predicting more optimal weights for athletic performers, including wrestlers (Tcheng and Tipton, 1973).

At least two groups of co-workers (Jackson and Pollock, 1976; Pollock et al, 1975; Wilmore and Behnke, 1969 and 1970) have demonstrated that anthropometric measurements can be used in assessing body density accurately. However, reliable skinfold and circumference measurements require much practise and skill on the part of the experimenter, and minor measurement errors can lead to substantial errors in the estimation of \% Fat when these measurements are used in predictive regression equations (Behnke and Wilmore, 1974).

Katch and others (1967) have developed a simple method for underwater weighing which can be performed in a swimming pool. Without some type of enclosure, water currents in a swimming pool often cause excessive scale fluctuations. In addition, a swimming pool is not always readily available for underwater weighing. The purpose of the present report is to describe the apparatus and technique for determining underwater weight in virtually any facility.

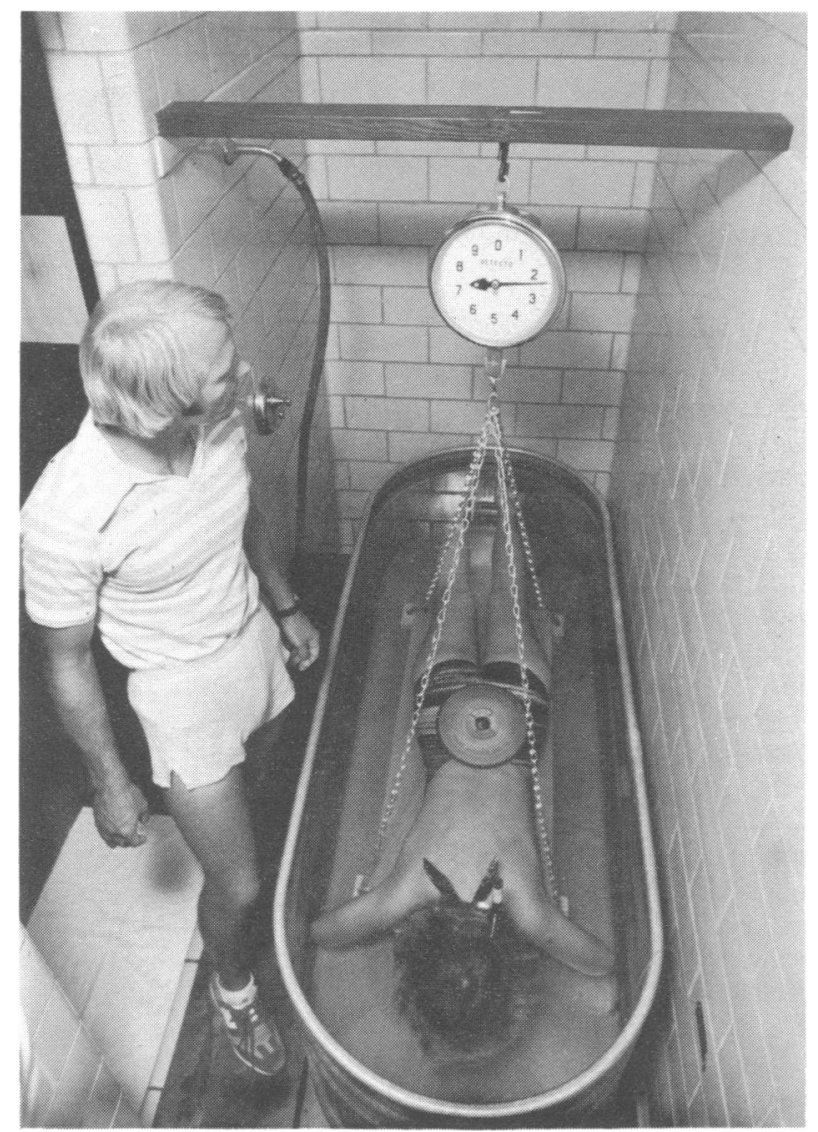

Figure 1. The underwater weighing apparatus with subject submerged. 


\section{METHOD}

\section{Apparatus}

The underwater weighing apparatus included a large, oblong livestock tank, $7 \mathrm{ft}$. long $\times 30$ in. wide $\times 2 \mathrm{ft}$. deep, figure 1. The tank was situated in one corner of a small shower room. It rested on four $4 \times 4$ in. boards which allowed for a drainage system underneath. (Most tanks will have a drainage plug.)

A $2 \times 4$ in. board was attached to the walls above and at the centre of the tank to support the scales and the subject platform. The support system also may be anchored at the ceiling.

The subject platform was made of $2 \times 4$ in. oak timber coated with a polyurethane wood finish. This completely prevented any uptake of water by the wood. The platform measured $20 \times 40$ in. To prevent floating, the apparatus was weighted at each corner with a painted $2 \frac{1}{2} \mathrm{lb}$. steel weight. Four $4 \mathrm{ft}$. lengths of medium weight chain were used to attach the subject platform to the autopsy scales.

The total cost of the building materials and tank was about $\mathbf{f 4 0}$. Autopsy scales can be purchased at prices ranging from $£ 60-£ 150$. (Chatillon, 83-30 Kew Gardens Rd., Kew Gardens, N.Y. 11415 and Detecto, 103-00 Foster Ave., Brooklyn, N.Y. 11236).

\section{Procedure}

The tank was washed with a germicidal detergent and rinsed with clean water before each use. Water temperature was taken before each weighing and maintained between $33^{\circ}$ and $35^{\circ} \mathrm{C}$. The subject reported to the laboratory after a partial fast of $\mathbf{2 4}$ hours and a total fast of three hours. Air weight was obtained on medical scales and vital capacity was measured using a standard wet respirometer. The subject then assumed a prone position across the platform in the tank. $A$ ten $\mathrm{lb}$. weight was positioned on the subject to keep the weight evenly distributed on the platform (see figure 1). A standard swimmer's snorkel and noseclip was used. The subject was allowed to practise breathing underwater and holding the breath after expiring maximally. After the subject was comfortable underwater, the experimenter signalled that he was ready, and the subject expired maximally. The breath was held in a maximally expired position for 5-10 seconds, and a reading was taken when scale fluctuations were no greater than $25-50$ grams $\cong$ 1-2 oz.). The subject then resumed normal breathing but remained submerged. This same procedure was repeated 3-4 times and then the subject surfaced. Following resubmergence, more weighings were taken until ten determinations were obtained. The mean of the last five readings was used in the underwater weight calculations.

\section{Calculations}

Two extraneous volumes must be measured or estimated; these include residual volume (RV) of the lungs after maximal expiration and gas or flatus in the gastrointestinal tract. The latter is seldom measured and a constant of 0.1 litre is used as an estimate for this volume (Behnke and Wilmore, 1974). RV can be measured accurately by oxygen or helium dilution techniques. However, equipment for such measurements is expensive.

Wilmore (1969) has shown that estimations of RV from vital capacity measurements or a constant RV resulted in similar \% Fat values as the RV measured by oxygen dilution. Thus, for the men $R V=0.24 \times$ Vital Capacity and for the women RV $=0.28 \times$ Vital Capacity. If vital capacity cannot be measured, then constant RV for the men $=1.3 \mathrm{I}$ and constant RV for the women $=1.0 \mathrm{I}$.

The body weight underwater $(W w)$ was the difference between the measured weight underwater and the weight of the apparatus plus noseclip, and the ten lb. weight. Body density was determined using the equation:

$D=\frac{W_{a}}{\frac{W_{a}-W_{w}}{D w}-(R V+0.1+S n V)}$

Where:

$\mathrm{D} \quad=$ body density $(\mathrm{kg} / \mathrm{l})$

$\mathrm{Wa}=$ body weight in air $(\mathrm{Kg})$

$W_{w}=$ body weight underwater $(\mathrm{Kg})$

$D w=$ density of water at specific temperature

RV = residual volume in litres

$\mathrm{SnV}=$ volume of air in snorkel in litres

The \% Fat can then be determined using the equation of Siri (1956) as suggested by Wilmore and Behnke 1969.

$\% \mathrm{Fat}=\left(\frac{4.95}{D}-4.5\right) \times 100$

TABLE I

Test - Retest Comparisons for \% Fat

$\begin{array}{lll}\text { Trial } 1 & \text { Trial } 2 & \text { Diff }\end{array}$

$\begin{array}{llll}\bar{X} & 16.41 & 16.35 & 0.87\end{array}$

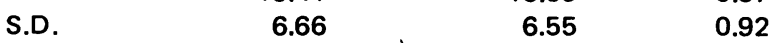

${ }^{a}$ Absolute difference between Trial 1 and Trial 2. 


\section{RESULTS AND DISCUSSION}

Twenty-eight college-aged students aged 18-22 were weighed underwater during two separate testing periods which were 24 to 48 hours apart. Test-retest differences for body density and \% Fat are presented in Table I. The values obtained for the weighings taken on different days were very similar with an average absolute difference between the two trials of $0.87 \%$ Fat. Reliability coefficients for ten weighings obtained on one of the test days are presented in Table II. Nearly all correlations were above 0.99 . The matrix does not illustrate the variability among the early trials observed by Katch and others (1967). However, standard deviations calculated for groups of adjacent trials did indicate that the first five trials (S.D. $=0.11$ ) were more variable than either the second five trials (S.D. $\mathbf{0 . 0 6}$ ) or the last three trials
$(S . D .=0.06)$.

The average \% Fat obtained for women $(N=9)$ was $22.2 \pm 5.9$ and for the men $(N=19)$ was $13.7 \pm 5.1$. These values agree well with those observed by such others as Jackson, Pollock, Wilmore and Behnke, for men and women college students.

The reliability and simplicity of the method allow its inclusion in standard class experiments.

\section{ACKNOWLEDGEMENTS}

The authors thank Mary Iten for her technical assistance and Dianne Lingle for help in preparing the manuscript. This research was supported in part by grants from the General Research Fund and the Biomedical Sciences Support Grant from the University of Kansas.

TABLE \|

Correlation Matrix for 10 Successive Trials. $\mathbf{N}=\mathbf{2 8}$

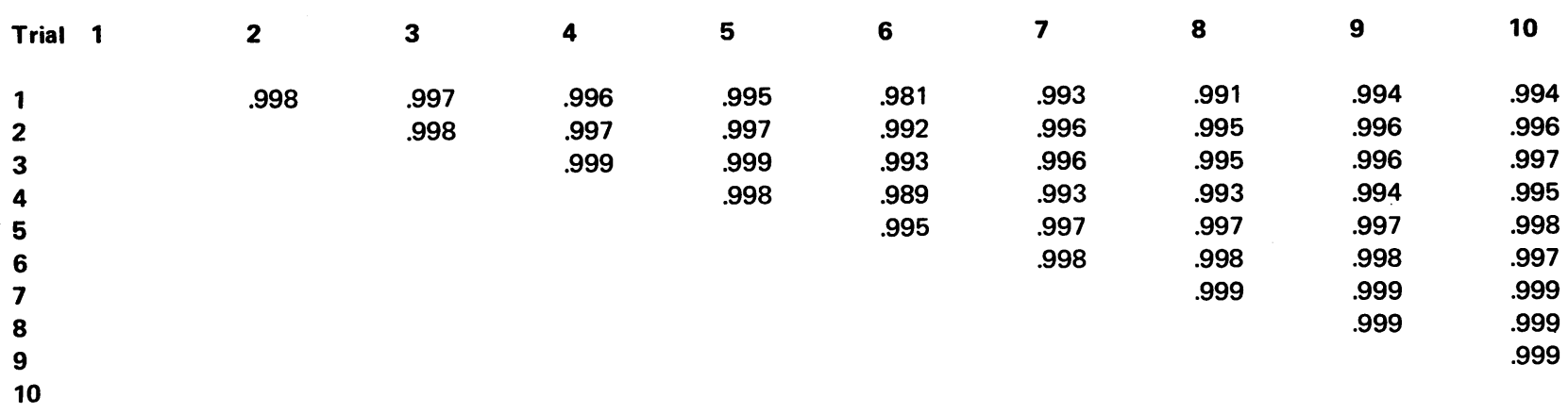

\section{REFERENCES}

Behnke, Albert R. and Wilmore, Jack H., 1974. Evaluation and Regulation of Body Build and Composition. Prentice-Hall, 20-27, Englewood Cliffs, New Jersey.

Jackson, Andrew S. and Pollock, Michael L., 1976. Factor analysis and multivariate scaling of anthropometric variables for the assessment of body composition. Med.Sci.in Sports 8: 196-203.

Katch, Frank, Michael, Ernest D. and Horvath, Steven M., 1967. Estimation of body volume by underwater weighing: description of a simple method. J.appl.Physiol. 23: 811-813.

Pollock, Michael L., Laughridge, Elizabeth E., Coleman, Beth, Linnerud, A. C. and Jackson, Andrew, 1975. Prediction of body density in young and middle-aged women. J.appl.Physiol. 38: 745-749.

Siri, W. E., 1954. Gross composition of the body. In Advances in Biol.and Med.Physics 4: 239. Academic Press, New York.

Tcheng, Tse-Kia and Tipton, Charles M., 1973. lowa wrestling study: anthropometric measurements and the prediction of a "minimal" body weight for high school wrestlers. Med.Sci.in Sports, 5: 1-10.

Wilmore, Jack H., 1969. The use of actual, predicted and constant residual volumes in the assessment of body composition by underwater weighing. Med.Sci.in Sports, 1: 87-90. 
Wilmore, Jack H. and Behnke, Albert R., 1969. An anthropometric estimation of body density and lean body weight in young men. J.appl.Physiol., 27: 25-31.

Wilmore, Jack H. and Behnke, Albert R., 1970. An anthropometric estimation of body density and lean body weight in young women. Am.J.Clin.Nutr., 23: 267-274. 